This is the author's Post-print version (final draft post-refereeing as accepted for publication by the journal). The definitive, peer-reviewed and edited version of this article is published as: Hedman L., van Ham M. and Manley D. (2011) Neighbourhood choice and neighbourhood reproduction. Environment and Planning A 43, 1381-1399. http://dx.doi.org/10.1068/a43453

\title{
Neighbourhood choice and neighbourhood reproduction
}

\author{
Lina Bergström¹, Maarten van Ham², David Manley ${ }^{3}$ \\ ${ }^{1}$ Institute for Housing and Urban Research, Uppsala University, Box 785, 80129 \\ Gävle, Sweden, email: lina.bergstrom@ibf.uu.se \\ ${ }^{2}$ Centre for Housing Research, School of Geography and Geosciences, University of \\ St Andrews, Irvine Building, North Street, St Andrews, Fife, KY16 9AL, UK, email: \\ maarten.vanham@st-andrews.ac.uk \\ ${ }^{3}$ Centre for Housing Research, School of Geography and Geosciences, University of \\ St Andrews, Irvine Building, North Street, St Andrews, Fife, KY16 9AL, UK, email: \\ d.manley@st-andrews.ac.uk
}

\begin{abstract}
Although we know a lot about why households choose certain dwellings, we know relatively little about the mechanisms behind their choice of neighbourhood. Most studies of neighbourhood choice only focus on one or two dimensions of neighbourhoods: typically poverty and ethnicity. This paper argues that neighbourhoods have multiple dimensions and that models of neighbourhood choice should take these dimensions into account. We propose the use of a conditional logit model. From this approach we can gain insight into the interaction between individual and neighbourhood characteristics which lead to the choice of a particular neighbourhood over alternative destinations. We use Swedish register data to model neighbourhood choice for all households which moved in the city of Uppsala between 1997 and 2006. Our results show that neighbourhood sorting is a highly structured process where households are very likely to choose neighbourhoods where the neighbourhood population matches their own characteristics. We find that income is the most important driver of the sorting process, although ethnicity and other demographic and socio-economic characteristics play important roles as well.
\end{abstract}

Keywords: neighbourhood, housing choice, sorting, residential mobility, conditional logit, Sweden

\section{Introduction}

There is now increasing empirical evidence that characteristics of the residential context play a role in explaining moving behaviour (Clark et al, 2006; van Ham and Clark, 2009; van Ham and Feijten, 2008). Both the socioeconomic status of neighbourhoods (Harris, 1999) and the ethnic mix of the neighbourhood population (Clark, 1992; Crowder, 2000) have been linked to residential mobility decisions. Most studies investigating the effect of neighbourhood characteristics on mobility behaviour focus on the actual moving decision, or on the desire to move away from certain neighbourhoods. Much less is known about how households choose their 
destination neighbourhood, and which neighbourhood characteristics play a role for which types of households in these decisions.

Developing a better understanding of neighbourhood choice is beneficial for a number of linked literatures. The housing choice literature focuses mainly on characteristics of dwellings. These dwelling characteristics are not independent from neighbourhood choice as different neighbourhoods offer different types of dwellings. An improved understanding of neighbourhood choice is also crucial for our understanding of neighbourhood change. Changes in the demographic or socioeconomic structure of neighbourhood populations can in part be explained through selective in- (and out-) flow of households. The literature on (the causes of) segregation will especially benefit from a better understanding of how households end up in certain neighbourhoods. Also the literature on neighbourhood effects will benefit from greater insight into the mechanisms which lead to selective inflows of households into neighbourhoods. The main challenge in the neighbourhood effects literature is to identify causal neighbourhood effects: selective inflows of households into neighbourhoods can bias models trying to measure neighbourhood effects (see, e.g., Bergström, forthcoming; Bergström and van Ham, 2011; Duncan et al, 1997; Galster, 2008; van Ham and Manley, 2010).

Despite the centrality of neighbourhood choice in a number of literatures, our knowledge of the mechanisms behind neighbourhood choice is limited. Previous studies suggest that most households move to areas where inhabitants' characteristics resemble their own (see the large body of literature inspired by Schelling, 1969; 1971), whether by choice (preferences) or due to limitations related to resources, discrimination, or the structure of the housing market. In fact, such neighbourhood sorting is to be expected in cities where neighbourhood characteristics or the relative status of neighbourhoods remains the same over time (see Meen, 2009). However, most previous studies have two important limitations. The first is that the choice set of alternative neighbourhoods is not taken into account. The choice for a particular (type of) neighbourhood cannot be understood without knowledge about the potential alternatives. The second problem is that neighbourhoods are generally characterised based on a limited number of characteristics. Studies typically model whether households move into a poverty neighbourhood or not, or into an ethnic concentration neighbourhood or not. The choice of a particular neighbourhood is often much more complicated than this basic conceptualisation allows (Bergström and van Ham, 2011). These two limitations are strongly related to the types of models used in studies of neighbourhood choice: typically binary or multinomial logit models which only allow for a limited number of outcome categories (neighbourhood types).

This paper contributes to the literature on neighbourhood choice by explicitly taking choice sets and multiple neighbourhood characteristics into account when modelling neighbourhood choice. We propose the use of a conditional logit model which allows us to investigate the choice of a specific neighbourhood (not a neighbourhood type), while taking multiple neighbourhood characteristics into account. Thus, this model allows us to estimate the effects of various neighbourhood characteristics on neighbourhood choice and sorting processes, while controlling for all others characteristics included in the model. We use data from the GeoSweden database, a register-based database with information on all individuals who has resided in Sweden since 1990. 


\section{Literature review}

The process leading to residential mobility is often conceptualised as two separate but related decisions; the choice of whether to move or not (sometimes subdivided in moving desires, intentions and plans), and (following that initial decision), the choice of destination (Brown and Moore, 1970). The primary driver of these decisions is household dissatisfaction with the existing dwelling in relation to household preferences and needs (Brown and Moore, 1970; Clark and Dieleman, 1996). The role of neighbourhood characteristics in mobility decisions has received less attention, but the body of literature which includes neighbourhood characteristics in models of residential mobility is growing (Clark and Ledwith, 2006; Clark et al, 2006; Feijten and van Ham, 2009; Kearns and Parkes, 2003; Lee et al, 1994; Permentier et al, 2009; van Ham and Clark, 2009; van Ham and Feijten, 2008). Studies investigating the second step in the decision making process (the choice of destination) have mainly focused on dwelling types (tenure, size, price) and less attention has been paid to location and neighbourhood characteristics. The choice of a particular dwelling in a particular neighbourhood is based on household preferences, resources and restrictions, and on the availability of dwellings. It can be argued that the choice of a particular neighbourhood is largely the result of the desire (or need) to live in a specific type (tenure, size, and price) of dwelling. There is large variation in the types (and quality) of dwellings available between neighbourhoods, making the supply of housing in different neighbourhoods a key explanatory factor behind neighbourhood sorting. However, there are clear indications in the literature that households also take neighbourhood attributes such as reputation, status, population composition, and location into consideration when choosing a dwelling (see for example Michelson, 1977; Permentier et al., 2009).

Households can only choose to live in a particular neighbourhood when there are vacant dwellings available. Vacancies are either the result of new construction or of households moving out of a dwelling (through mobility or death). A move into a vacant dwelling often generates a vacancy chain spreading through different types of neighbourhoods as moving households leave vacant dwellings themselves (see Magnusson, 1994). This relocation (and spatial redistribution) of households is part of the neighbourhood sorting process as household characteristics change and move to areas that better match their current preferences, resources and restrictions. Neighbourhood characteristics are thus reproduced (see e.g. Friedrichs, 1991; Andersson and Bråmå, 2004 for studies on the reproduction of poverty neighbourhoods). Bailey and Livingstone (2007) have shown that the primary drivers of vacancy rates are demographic mix and housing stock characteristics (see also van Ham and Clark, 2009). Neighbourhoods dominated by younger age groups, single adults, and with a high proportion of dwellings in the rental sectors are likely to have the highest turnover rates. Such neighbourhoods are also associated with lower income groups and tend to have higher proportions of non-native residents (Andersson and Bråmå 2004; van Ham and Clark 2009).

Financial resources are an important driver of neighbourhood choice. Buying a house, or buying into the cooperative housing segment in Sweden, requires substantial down payments, making neighbourhoods where such dwellings dominate virtually inaccessible to households with limited resources. The Swedish housing market is highly segmented, leading to an uneven distribution of socio-economic and ethnic groups within different types of housing and tenure. For instance, immigrants from non-western countries, who generally have limited resources, are over-represented in 
the rental segment (Andersson et al, 2007; Murdie and Borgegård, 1998). Previous studies using Swedish data have emphasized the role of (spatial) segmentation when explaining ethnic residential segregation. As expressed by Andersson and colleagues (2007, p.5), "the geographic distribution of tenure forms and housing types within a city or region is $[\ldots]$ a fundamental condition for the segregation process". However, there is also evidence of ethnic segregation within tenure segments in Sweden (see Bråmå et al., 2006). This is influenced by differences in prices between neighbourhoods and, for the rental segment, waiting times required to successfully secure a dwelling. In Uppsala, waiting times vary from around two years up to ten years or longer, reflecting the attractiveness of different areas. It should be noted that rents in Sweden are set according to property size and standard rather than direct market value. The international literature emphasises the effect of income on neighbourhood sorting. For instance, Clark and Ledwith (2006) analysed moving desires and actual moves in Los Angeles, using longitudinal data collected in 2002. They concluded that the greatest driver of neighbourhood sorting for both Whites and Hispanics remains household income. Other studies have emphasized how limited financial resources prevent people from exiting areas with high levels of poverty (Bolt and van Kempen, 2003; Kearns and Parkes, 2003; South and Crowder, 1997; 1998). We simply note that households with fewer available resources will have more restricted choice sets, and that some households will have very limited choice sets. We thus hypothesize that households sort into neighbourhoods according to socioeconomic characteristics (income, education, employment status, use of benefits (Hypothesis 1).

Neighbourhood choice has been associated with the ethnic composition of the neighbourhood population. Starting with the work of Schelling $(1969 ; 1971)$ it has been argued that many households have a preference for living in neighbourhoods with households of similar ethnic background and that these preferences can lead to highly segregated neighbourhoods. Clark (1991) used data for the United States to demonstrate that the Schelling hypothesis was broadly correct, and that even small differences in preferences between ethnic groups with regard to the ethnic composition of neighbourhoods can lead to highly segregated communities (see also Fossett, 2006). Evidence from both Europe and the United States indicate that ethnic segregation is primarily driven by own-group preferences held by the majority population. In addition, the majority population tends to have the greatest level of resources and therefore, the ability to put these preferences in to action. For example, Clark (1991) reports that while whites preferred the ethnic mix in their neighbourhood to be at least $80 \%$ white, blacks seemed to prefer a 50/50 mix. In Sweden, most immigrant-dense neighbourhoods are truly multicultural, making the notion of voluntary ethnic minority clustering unlikely. Ethnic mix preferences (or rather preferences for relative homogeneity) by the majority population is apparent at the aggregate level through patterns of white avoidance of ethnic minority neighbourhoods (Bråmå, 2006).

Studies from various countries have found that ethnic minorities are more likely than natives to move to ethnic concentration neighbourhoods. It has been hypothesised that these moves to ethnic concentration neighbourhoods are (partly) motivated by the desire to live in areas with others who have common life experiences and by the availability of ethnic specific services (see Bowes et al, 1997). Other studies have emphasized the impact of socio-economic differences between ethnic and non-ethnic groups (e.g. Clark and Ledwith, 2006; South and Crowder, 1997; 1998). In Sweden ethnic minorities are overrepresented among the lower-income 
groups, and as a result they concentrate in low cost neighbourhoods (see Bolt et al, 2008, for a similar explanation for the Netherlands). Bråmå and Andersson (2005; 2010) have shown that recent immigrants in Sweden initially move to areas with high densities of immigrants. When their income improves they are more likely to leave these neighbourhoods and move to less ethnically concentrated neighbourhoods. Discrimination has also been shown to influence neighbourhood ethnic sorting (e.g. Turner et al, 2002, for the United States), although the extent to which this is valid for Sweden is unclear (Bråmå, 2007). Based on the above literature review, we hypothesise that households sort into neighbourhoods based on their ethnicity, with foreign born households being more likely to move to immigrant-dense neighbourhoods compared to native Swedes (Hypothesis 2).

There is a large literature showing how the propensity to move and the choice of dwellings is affected by life course factors. The literature emphasises the relationships between housing choice and the need for space and household and socioeconomic change over the life course (see Clark and Dieleman, 1996; Clark and Huang, 2003). Changes in household composition are often associated with moves to different types of dwellings in different types of neighbourhoods. Preferences, resources and constraints all change over the life course. In general, young adults and singles prefer to live in city centres, while households with children prefer to live in suburbs. Households with children generally prefer to live in a neighbourhood with many other children, with good access to (high quality) services such as schools and playgrounds, and with dwellings that match the needs of the family (see Clark and Dieleman, 1996). Based on the above we hypothesise that households sort into neighbourhoods according to demographic characteristics, for example, households with children are more likely to move to neighbourhoods with a high proportion of households with children (Hypothesis 3).

The literature review has highlighted a range of factors which influence neighbourhood choice. Most of these factors have been studied in isolation while in reality households 'buy' a bundle of neighbourhood attributes when moving to a particular neighbourhood. The literature review suggests that neighbourhood sorting is a highly structured process where households generally move to neighbourhoods with populations similar to their own characteristics. The main contribution of this paper is that we model neighbourhood choice by explicitly taking choice sets and multiple neighbourhood characteristics into account, where other studies modelled moves to neighbourhood types based on one or two neighbourhood characteristics only. Using a conditional logit model we can test whether income is still a significant driver of sorting after controlling for demographic, ethnic and other forms of socioeconomic sorting.

\section{Data and Methods}

The majority of studies investigating neighbourhood choice employ binary logistic regression or generalized multinomial logit models. The disadvantage of these types of models is that they only allow for a restricted number of neighbourhood characteristics to be taken into account: typically the level of deprivation and/or the level of concentration of ethnic minorities in the neighbourhood. This highly reductionist approach limits our understanding of how households choose neighbourhoods as neighbourhoods have multiple dimensions, and these dimensions can be expected to interact with household characteristics. 
In this paper we adopt a statistical model that allows for both large choice sets and multiple characteristics of destinations. We model neighbourhood choice using a conditional logit model (CLM) (McFadden, 1974; see also Hoffman and Duncan, 1988, which includes a comparison to multinomial logit models). The CLM has been widely used in biomedical research, but also in the social sciences, especially in studies of transportation demand and consumer choices. Few previous studies have used CLM to investigate residential mobility and neighbourhood choice (notable exceptions are Ioannides and Zabel, 2008; Quillian and Bruch, 2010). The CLM is closely related to the generalized multinomial model but where the multinomial model treats neighbourhood choice as a function of household ${ }^{1}$ characteristics, the CLM treats neighbourhood choice as a function of the characteristics of the alternatives (potential destinations). The comparison in a CLM is made within rather than between households, as would be the case in a multinomial logit, estimating the probability that household $i$ will choose alternative $j$ among a set of alternative neighbourhoods. Thus, let $\mathrm{P}_{\mathrm{ij}}$ denote the probability that household $i$ will choose alternative $j$, based on the characteristics of the of the $j^{\text {th }}$ alternative $\left(\mathrm{N}_{\mathrm{j}}\right)$, and given the set of alternatives (the choice set, $\mathrm{C}_{(\mathrm{i})}$ ) for the $i^{\text {th }}$ household. The choice of the $j^{\text {th }}$ alternative is related to the other alternatives in the choice set and their characteristics $\left(\mathrm{N}_{\mathrm{k}}\right)$. Following Hoffman and Duncan (1998), the conditional logit model is written:

$$
P_{i j}\left(N_{j}, C_{(i)}\right)=\exp \left(\beta N_{j}\right) / \sum_{k=1}^{K} \exp \left(\beta N_{k}\right)
$$

The CLM estimates the probability that a household chooses a particular neighbourhood (as represented by $\mathrm{N}_{\mathrm{j}}$ ) from a choice set of neighbourhoods (as represented by $\mathrm{C}_{(\mathrm{i})}$ ), based on neighbourhood characteristics. When modelling neighbourhood choice it is also important to take household characteristics into account. In a CLM, household (or individual) characteristics are invariant across the household's choice set. Thus, in order to obtain variation on the household level and be able to include household characteristics in the model, they must be interacted with neighbourhood characteristics. We can include this in equation 1 by letting $\mathrm{X}_{\mathrm{i}}$ denote the characteristics of the $i^{\text {th }}$ household.

$$
P_{i j}\left(N_{j}, X_{i}, C_{(i)}\right)=\exp \left(\beta N_{j} X_{i}\right) / \sum_{k=1}^{K} \exp \left(\beta N_{k} X_{i}\right)
$$

We measure both household and neighbourhood characteristics at time $t$ - 1 , the year before the actual move took place. This is important to identify the causal path between household and neighbourhood characteristics and actual moves. If characteristics where measured at time $t$, it would be impossible to determine whether households' characteristics were the cause or result of a move. The probability that the $i^{\text {th }}$ household will choose the $j^{\text {th }}$ alternative, or in other words, will live in neighbourhood $j$ at time $t$, is thus written:

$$
P_{i j t}\left(N_{j_{(t-1)}}, X_{i_{(t-1)}}, C_{(i)}\right)=\exp \left(\beta N_{j_{(t-1)}} X_{i_{(t-1)}}\right) / \sum_{k=1}^{K} \exp \left(\beta N_{k_{(t-1)}} X_{i_{(t-1)}}\right)
$$

\footnotetext{
${ }^{1}$ In terms of neighbourhood choices, it can be argued that decisions are made at a household level, rather than at the level of the individual.
} 
We model neighbourhood choice for individuals residing in Uppsala, a medium-sized Swedish city (140,000 inhabitants) located about $80 \mathrm{~km}$ north of Stockholm. Most previous studies of residential mobility and neighbourhood choice in Sweden and elsewhere focus on larger cities with more extreme differences in poverty levels and ethnic composition between neighbourhoods. Small and Feldman (2011) note that most neighbourhood effect studies also have been carried out in such (nonrepresentative) cities and call for more research on smaller, average, and underresearched cities. Uppsala is such a city: for example, the share of immigrants in the municipality is $13 \%$, only slightly higher than the national average $(12 \%)$. It can be expected that the sorting effects found for the "average" city of Uppsala can also be found in larger cities, while the opposite is not always the case.

The data used in this study are obtained from the GeoSweden database, a longitudinal register-based database with information on all individuals who have resided in Sweden at some point since 1990. It is collected by Statistics Sweden from various public records and is updated annually. The GeoSweden database includes demographic, socio-economic and geographic information (geo-coded to a 100 by 100 meter grid) which makes it possible to identify and track movers. For this study we have aggregated the individual level data in GeoSweden to a household level. We selected all households that had moved either within or into the city of Uppsala between 1997 and 2006. Those who left Uppsala are excluded from the dataset. A move is defined as a change of $100 \mathrm{~m}^{2}$ grid between two consecutive years. The ten years of data correspond to nine years of moving data, 1997/1998 through to 2005/2006. The total number of household moves in data was 130,281.

Although the GeoSweden data is unusually rich for register data, there are some limitations. For example, the information on dwellings is very limited, which means that we cannot include any information such as dwelling size or costs. There are also limitations with respect to the household data. Couples can only be identified in the dataset if they are married, registered partners or have a dependent child in common. As a result, cohabiting couples without children will be observed as (two) single households. Since cohabiting is common in Sweden, especially in the young (and mobile) age groups, the number of moving households will be exaggerated (the data will contain too many moving singles). Since GeoSweden is based on individual data, we can also follow household changes - household formation and dissolution which are often related to mobility. Such moves are also included in our dataset and make up $21 \%$ of the moves. For these moves, we have used household characteristics of the year of the move, not the previous year, to avoid measuring the characteristics of the former household. The data also has limitations regarding the definition of unemployed individuals as the non-employed group is heterogeneous and includes unemployed individuals, students, retired people and other non-working individuals. We have defined unemployment as individuals in working ages (20-64) that are not employed or do not receive student funding. Notwithstanding these limitations, we feel that the quality, breadth and extent of the data is sufficient to enable meaningful analysis.

The most appropriate definition of neighbourhoods in studies of neighbourhood choice is highly contested (see discussions by Galster, 2001; Kearns and Parkinson, 2001; Manley et al, 2006). Several different spatial levels have been used to identify neighbourhoods in the literature but the most common are census tracts, postal codes, or equivalent administrative divisions. We make neighbourhoods operational using the Swedish SAMS (Small Area Market Statistics) areas. These have been used to approximate neighbourhoods in previous studies using the same 
GeoSweden database (for example Andersson and Bråmå, 2004; Bråmå and Andersson, 2005; 2010; Galster et al, 2008). We have excluded all SAMS (herein referred to as neighbourhoods) from the choice set of neighbourhoods with a population of less than 50 inhabitants (mostly commercial and industrial areas). We have also removed all moves into these neighbourhoods. The total number of neighbourhoods included in the analysis in 2001 (the midyear of the period under investigation) is 122. They contain 1103 individuals on average (see Table 1). Since neighbourhood populations change between years, in some cases dramatically as a result of new dwelling construction or old dwelling demolition, the number of neighbourhoods included in the choice sets varies between the years, from 120 (in 2000) to 123 (in 2004 and 2005). We have included moves between and within neighbourhoods, which resulted in a total of 130,231 moves in our dataset.

For each moving household we constructed a choice set of neighbourhoods in Uppsala. Since we do not have access to the actual alternatives considered by households, we have chosen to randomize the choice sets. We have chosen to limit the choice set to ten neighbourhoods per household; the destination neighbourhood and nine randomly chosen alternative neighbourhoods in Uppsala. Given that each household could theoretically consider any neighbourhood, the randomised choice set is a suitable approximation to reality. An alternative approach would have been to include all neighbourhoods in Uppsala in the choice sets. We argue that this is suboptimal for two reasons. First, it is less realistic since it is unlikely that households actually consider all neighbourhoods when planning to move. Second, it is problematic from a modelling perspective since several alternatives in the full choice set will have very similar characteristics. However, to test the robustness of the model with random choice sets, we also ran a model using a $25 \%$ population sample with all neighbourhoods included in the choice sets (see appendix A).

To account for the unequal distributions of moving opportunities between neighbourhoods - in larger neighbourhoods it is more likely that a vacancy becomes available during a given time span than in smaller neighbourhoods - the alternatives in the choice set are weighted according to the number of vacancies (defined by the number of households moving out of the neighbourhood) during the year of the move, using the total number of vacancies over all neighbourhoods in the particular year as denominator.

The CLM includes a set of household and neighbourhood characteristics as independent variables. All household level variables (ethnic composition, family composition, whether there is a student in the household, highest level of education, employment status, family disposable income, benefit status, and tenure) in the model are transformed into dichotomous categories. Ethnic composition can be Swedish, if all adult members are Swedish born, foreign born, if all adult members are foreign born, or mixed. Employment status is calculated in a similar way. Education level is the highest level in the household, student is coded as 1 if any of the adult household members are students, while the remaining variables directly relate to households in the GeoSweden data. Neighbourhood level variables are included as the proportion of the population belonging to that group. The only exception is median neighbourhood income, which is included as a continuous variable. We have then interacted each set of household variables with their equivalent variable on the neighbourhood level. For example, the median neighbourhood income is interacted with each of the five income quintiles on the household level, while the proportion of inhabitants that are foreign born in the neighbourhood is interacted with the ethnic categories on the household level (all adults born in Sweden, all adults being foreign born, or mixed). 
Table 1 presents the variable summary statistics for neighbourhood characteristics in 2001 (the midyear of the period under investigation), including the proportion of foreign born, households with children under age 18, students living in the neighbourhood, people with low education (no high school degree), non-employed (including individuals in working ages that are neither employed nor students), people receiving social benefits, people living in public rented dwellings, and median household disposable income (continuous). Table 2 presents summary statistics for the characteristics of moving households and all households who lived in Uppsala in 2001. The Table shows that foreign born residents, singles, students, non-employed, and receivers of benefits are overrepresented among movers.

\section{$<<<<<$ Table 1 about here $>>>>>$}

\section{$<<<<$ Table 2 about here $\gg>>>$}

\section{Results}

To get an idea of the distribution of vacancies in Uppsala, we calculated the share of households moving within or away from their neighbourhood (in 2001). In Uppsala, turnover rates vary from 0 to $46.5 \%$ with a mean of $15 \%$, meaning that about $1 / 7$ of the population in an average neighbourhood moved during 2001. In Table 3 we show the characteristics of neighbourhood populations for 5 types of neighbourhoods, based on quintiles of population turnover rates. Neighbourhoods in the highest turnover quintile group (quintile 5) have a mean turnover rate of $26.8 \%$. Further investigation reveals that the most mobile neighbourhoods are typically student areas; the proportion of students in these neighbourhoods is almost twice as high as in the areas in the second highest turnover quintile (quintile 4).

\section{$<<<<$ Table 3 about here $>>>>>$}

Table 3 also shows almost linear associations between turnover rates and a number of neighbourhood characteristics: the higher the share of foreign born, non-employed people, and people on social benefits, and the lower the share of households with children, and median income in the neighbourhood, the higher turnover rates are. The associations between turnover rate, income and ethnicity are shown in Figure 1, where each variable above has been transformed into quintiles. The darker shaded areas are neighbourhoods where turnover rate (1a), median income (1b) or the share of foreign born (1c) is high.

\section{$<<<<<$ Figure 1 about here $>>>>>$}

Table 4 presents the results of the conditional logit model of neighbourhood choice using a choice set of 10 neighbourhoods. Appendix A shows modelling results using a $25 \%$ random selection of all moves with a choice set of all neighbourhoods in Uppsala. The results of the model in Appendix A and Table 4 are very similar, indicating that our results are robust.

In Model 1 (Table 4) we only included the interaction effect between median neighbourhood income and household income in quintiles (the $1^{\text {st }}$ quintile includes households with the lowest incomes). In the literature review we hypothesized income to be a major driver of neighbourhood sorting because income will be the main 
constraint regarding access to better neighbourhoods. We find that with increasing income in the neighbourhood, households with the lowest incomes are the least likely to move there, and households with the highest incomes are the most likely to move there. The interaction effect of neighbourhood and household income explains over 12 percent of the total variation in neighbourhood choice, which is relatively high since Model 2 - including a range of other interaction effects - explains just over 18 percent. We have also ran models including each of the other variables separately (results not shown). These models show evidence of clear sorting for all neighbourhood characteristics, but the model fit is not as good compared to the model only including income; R-square values varied between 0.066 (share of students) and 0.007 (share of public renters).

\section{$\ll<<<$ Table 4 about here $\gg>>>$}

Model 2 shows that after including other interaction effects, the gap between the different income groups is somewhat reduced compared to Model 1. Nevertheless, the differences between the household income categories remain significant and show the same linear pattern. Also the other interaction effects demonstrate that households are likely to choose neighbourhoods with populations similar to themselves, and avoid neighbourhoods where inhabitants are different. The interaction effect between the share of foreign born people in the neighbourhood and household ethnic composition shows that households with only Swedish born people are the least likely to move to a neighbourhood with a high share of foreign born. The foreign born (households where all adult members were born outside Sweden) are more likely to move to a neighbourhood with a high share of foreign born. As would be expected given these results, mixed ethnic households are between these two groups. These results confirm that neighbourhood sorting based on ethnic background takes place in Sweden. The underlying mechanism is very likely to be preferences or discrimination as we control for other household and neighbourhood characteristics such as income and household composition. The results also show how ethnic segregation is caused and maintained through selective neighbourhood sorting by ethnicity.

Families with one or more children are the most likely of all household categories to move to neighbourhoods with a high percentage of households with children. Singles without children are the least likely to move to neighbourhoods with a high percentage of households with children. Student households (where at least one member of the household is registered as a student) are more likely to move to neighbourhoods with a high percentage of students than households without any students. Households without any students seem to avoid student areas. It should be noted that in some neighbourhoods high concentrations of student accommodation can be found. These neighbourhoods are less likely to attract other types of households because the accommodation is neither suitable nor available for them. The effect of the housing market will be further discussed in the conclusion of this paper.

Households without anyone with a high school degree are the most likely to move to neighbourhoods with a high share of people with a low level of education. Households with at least one person with a university degree are the least likely to move to neighbourhoods with a high percentage of people with a low level of education. A similar pattern can be observed for the interaction effect between the neighbourhood level of non-employment and the employment status of households (households being fully employed, fully unemployed, mixed, or where the members are of age 65 or older). Although all coefficients are negative and the differences are 
very small, we find that employed households are less likely to move to neighbourhoods with a high proportion of unemployed individuals. Likewise, households not in receipt of social benefits avoid neighbourhoods with a high proportion of households on benefits. The coefficients for the tenure interactions are all very small, indicating that the tenure a household resides in prior to the move has little influence on the choice of neighbourhood, after controlling for all the other interactions. The results show a small tendency for public renters to move to neighbourhoods which already have a high share of public rental residents. Conversely, home owners are those most likely to avoid public rental neighbourhoods, followed by households living in cooperatives and private renters.

Our results show clear indications of a structured neighbourhood sorting process. $^{2}$ Households consistently choose neighbourhoods that match their own characteristics, and they do so for all neighbourhood characteristics included in Model 2. It is important to note that the sorting patterns for each neighbourhood characteristic are controlled for the effects of other neighbourhood characteristics in the model. So, for example, we find evidence for ethnic sorting after controlling for income sorting (interaction effect between personal income and median neigbourhood income) and other dimensions of sorting. Although some variables appear to have a small impact on the sorting process, especially in comparison to income, the patterns are consistent. The results strongly suggest that neighbourhood characteristics are reproduced through selective mobility of households.

\section{Discussion}

This paper contributes to the literature on neighbourhood choice by explicitly taking choice sets and multiple neighbourhood characteristics into account when modelling neighbourhood choice. This is one of the first studies of neighbourhood choice to use a conditional logit model. The main advantage of this model is that it allowed us to investigate the choice for a specific neighbourhood, while taking multiple neighbourhood characteristics into account. By using a conditional logit model we can investigate several sorting mechanisms simultaneously (while controlling for the others), where other studies only investigated one or two dimensions of sorting. The modelling results indicate that moving patterns are highly structured and that households are likely to move to neighbourhoods where the population has similar characteristics as themselves (supporting hypotheses 1, 2 and 3). We have found this to be valid for all combinations of household and neighbourhood characteristics included in the model.

The results clearly indicate that the neighbourhood choices made by moving households result in the reproduction of neighbourhood characteristics over time. It is important here to stress that the concept of choice needs to be used with caution. Households make choices within a restricted choice set. Choices are restricted by household preferences, resources and restrictions, but also by constraints imposed by the structure of the housing market. It is very likely that poor households do not 'choose' to move to poverty neighbourhoods, but move there because they cannot afford to live anywhere else (van Ham and Manley, 2009; 2010). Their level of choice

\footnotetext{
${ }^{2}$ We have also ran the model separately for different age groups (18-29, 30-44, 45-64, and 65+) and the pattern hold for all groups although the explanatory power of the models varies. The best model fit was achieved for the youngest age group ( $\mathrm{R}$-square of 0.26 ), which we believe is due to this group being the most restricted in their housing market choices.
} 
is seriously reduced due to a lack of realistic alternatives. Drawing on previous literature, we suggest that the sorting patterns found are due to a combination of household preferences and resources and the opportunity structure of the housing market. The opportunity structure of the housing market refers to the geographical distribution of dwellings of different types and tenures as well as the rules and regulations of the housing market. This opportunity structure is especially limited for low-income groups, in particular those new in the city or country. Indeed, the results indicate that household income is a key characteristic influencing neighbourhood sorting in Sweden. We also find evidence of sorting for other socioeconomic characteristics; level of education, employment status and dependency of social welfare. The finding that households with children move to neighbourhoods with a high share of households with children can also be explained by a combination of opportunity structure and household preferences and resources. Neighbourhoods which have a high proportion of children in their population are places where these families are most likely find a suitable dwelling, as well as being places which match parents preference to live in a child friendly neighbourhood. The effect of ethnicity is more complicated: the fact that we control for tenure, neighbourhood income, and household composition suggest that own-group preferences, whether among the majority or minority groups, and discrimination most likely play an important role in the neighbourhood sorting process (see also Schelling, 1969; 1971; Clark, 1992).

Our findings on neighbourhood sorting are beneficial for literatures on housing choice, neighbourhood change, segregation, and neighbourhood effects. The neighbourhood effects literature can benefit from a more in-depth understanding of sorting processes as selective mobility into neighbourhoods hinders the identification of causal neighbourhood effects (Bergström and van Ham, 2011). To assess whether neighbourhood deprivation has a causal effect on individual outcomes, such as employment outcomes, it is crucial to take into account that unemployed people are more likely to move to deprived neighbourhoods in the first place (see van Ham and Manley, 2010). In this paper we have shown that residential mobility is highly selective, that neighbourhood sorting is highly structured, and that mobility is highest in the deprived neighbourhoods that tend to be the focus of much neighbourhood effects research. Our results indicate that people living in poverty areas were likely to be poor at the time of entry into these neighbourhoods. This finding undermines any claim of causality when studying the effects of living in deprived neighbourhoods on individual poverty if neighbourhood sorting is not explicitly controlled for. Furthermore, high turnover rates, which were found especially in student and lowincome areas, mean that exposure times in these neighbourhoods tend to be short and that the neighbourhoods do not provide stable environments even for those staying put. High mobility rates mean that neighbourhood transmission mechanisms that require a certain amount of exposure to the same people are less likely to take place (see for instance Bergström, forthcoming; Galster, 2011). The results of this study demonstrate a need for a more sophisticated approach when modelling neighbourhood effects, an approach which explicitly takes neighbourhood sorting (and preferably also turnover rates) into account.

Sweden is internationally known for being a relatively 'equal' society, whether it comes to income or opportunities. The Swedish housing market further enhances this picture, at least when it comes to the rental housing market. The public rental segment is open to everyone, is relatively attractive compared to the social housing estates and poverty neighbourhoods found in parts of Europe and the U.S., and rent levels are not market driven. Nevertheless, we have found clear evidence of 
neighbourhood sorting according to demographic, socio-economic and ethnic dimensions in Sweden, and this suggests that neighbourhood sorting is structural within housing markets and cannot be ignored.

\section{Acknowledgements}

This paper was written whilst Lina Bergström was a visiting researcher at the Centre for Housing Research (CHR) at the University of St Andrews. We acknowledge the financial support of CHR which made this stay possible.

\section{References}

Andersson R, Bråmå A, 2004, "Selective Migration in Swedish Distressed Neighbourhoods: Can Area-based Urban Policies Counteract Segregation Processes?" Housing Studies 19 517-539

Andersson R, Hogdal J, Johansson S, 2007, Planering för minskad boendesegregation, Rapport 2007:1, Regionplane- och trafikkontoret (Stockholms läns landsting: Stockholm)

Bailey N, Livingston M, 2007, Population Turnover and Area Deprivation (Joseph Rowntree Foundations: Bristol)

Bergström L, (forthcoming), "The Impact of Residential Mobility on Measurements of Neighbourhood Effects" Housing Studies

Bergström L, van Ham M, 2011, "Understanding neighbourhood effects: selection bias and residential mobility", in Neighbourhood Effects Research: New Perspectives Eds M van Ham, D Manley, N Bailey, L Simpson, D Maclennan (Dordrecht: Springer)

Bolt G, van Kempen R, 2003, "Escaping Poverty Neighbourhoods in the Netherlands" Housing, Theory and Society 20 209-222

Bolt G, van Kempen R, van Ham M, 2008 "Minority Ethnic Groups in the Dutch Housing Market: Spatial Segregation, Relocation Dynamics and Housing Policy" Urban Studies 45 1359-1384

Bowes A, Dar N, Sim D, 1997, "Tenure preference and housing strategy: an exploration of Pakistani experiences" Housing Studies 12 63-84

Bråmå Å, 2006, “'White flight'? The production and reproduction of immigrant concentration areas in Swedish cities, 1990 - 2000" Urban Studies 43 11271146

Bråmå A, 2007, Etnisk diskriminering på bostadsmarknaden. En forskningsöversikt, IBF Working paper no 54 (Gävle: Institute for Housing and Urban Research)

Bråmå Å, Andersson R, 2005, “Who leaves Sweden's large housing estates?” in Restructuring large housing estates in Europe Eds R van Kempen, K Dekker, S Hall, I Tosics (The Policy Press: Bristol)

Bråmå A, Andersson R, Solid D, 2006, Bostadsmarknadens institutioner och grindvakter $i$ den etniskt segmenterade staden - exemplen Stockholm och Uppsala. Appendix to Rapport Integration 2005 (Norrköping: Board of Integration).

Bråmå A, Andersson R, 2010, "Who leaves rental housing? Examining possible explanations for ethnic housing segmentation in Uppsala, Sweden" Journal of Housing and the Built Environment, Published online: DOI: 10.1007/s10901010-9179-4. 
Brown L A, Moore E G, 1970, "The Intra-Urban Migration Process: A Perspective" Geografiska Annaler B 52 1-13

Clark W A V, 1991, "Residential Preferences and Neighborhood Racial Segregation: A Test of the Schelling Segregation model" Demography 28 1-19.

Clark W A V, 1992, "Residential preferences and residential choices in a multiethnic context" Demography 29 451-466

Clark W A V, Deurloo M, Dieleman F, 2006, "Residential Mobility and Neighbourhood Outcomes" Housing Studies 21 232-342

Clark, W A V, Dieleman F M, 1996, Households and Housing: Choice and Outcomes in the Housing Market (CUPR Press: New Brunswick)

Clark W A V, Huang Y, 2003, "The life course and residential mobility in British Housing markets" Environment and Planning A 35 323-339

Clark W A V, Ledwith V, 2006, "Mobility, housing stress and neighbourhood contexts: evidence from Los Angeles" Environment and Planning A 38 10771093

Crowder K, 2000, "The racial context of white mobility: an individual-level assessment of the white flight hypothesis" Social Science Research 29 223-257

Duncan G, Connell J, Klebanov P, 1997, "Conceptual and methodological issues in estimating causal effects of neighborhoods and family conditions on individual development" in Neighborhood Poverty: Vol. 1 Context and Consequences for Children Eds J Brooks-Gunn, G Duncan, J Aber (Russell Sage Foundation: New York)

Feijten P, van Ham M, 2009, "Neighbourhood change ... reason to leave?" Urban Studies 46 2103-2122

Fosset M, 2006, "Including Preference and Social Distance Dynamics in Multi-Factor Theories of Segregation" Journal of Mathematical Sociology 30 289-298

Friedrichs, J, 1991, "Middle-class leakage in large new housing estates: empirical findings and policy implications" Journal of Architectural and Planning Research 8 287-295.

Galster G, 2001, "On the Nature of Neighborhood" Urban Studies 38 2111-2124

Galster G C, 2008, "Quantifying the Effect of Neighbourhood on Individuals: Challenges, Alternative Approaches, and Promising Directions" Journal of Applied Social Sciences, Schmollers Jahrbuch 128 1-42

Galster G, 2011, "The Mechanism(s) of Neighborhood Effects. Theory, Evidence, and Policy Implications", in Neighbourhood Effects Research: New Perspectives Eds M van Ham, D Manley, N Bailey, L Simpson, D Maclennan (Dordrecht: Springer)

Galster G, Andersson R, Musterd S, Kauppinen T, 2008, "Does Neighborhood Income Mix Affect Earnings of Adults? New Evidence from Sweden" Journal of Urban Economics 63 858-870

Harris D R, 1999, “'Property values drop when blacks move in, because ...': racial and socioeconomic determinants of neighborhood desirability" American Sociological Review 64 461-479

Hoffman S D, Duncan G J, 1988, "Multinomial and Conditional Logit DiscreteChoice Models in Demography" Demography 25 415-427

Ioannides Y M, Zabel J E, 2008, "Interactions, neighborhood selection and housing demand" Journal of Urban Economics 63 229-252

Kearns A, Parkes A, 2003, "Living in and leaving poor neighbourhoods in England" Housing Studies 18 827-851 
Kearns A, Parkinson M, 2001, "The significance of neighbourhood" Urban Studies 38 2103-2110

Lee B A, Oropresa R S, Kanan J W, 1994, "Neighborhood Context and Residential Mobility" Demography 31 249-270

Magnusson L, 1994, Omflyttning på den svenska bostadsmarknaden. En studie av vakanskedjemodeller (Geografiska Regionstudier nr 27, Uppsala)

Manley D, Flowerdew R, Steel D, 2006, "Scales, levels and processes: studying spatial patterns of British census variables" Computers, Environment and Urban Systems 30 143-160

McFadden D, 1974, "Conditional logit analysis of qualitative choice behaviour", in Frontiers in econometrics Ed P Zarembka (Academic Press: New York)

Meen, G. (2009) "Modelling Local Spatial Poverty Traps in England" Housing Studies 24 127-147

Michelson W, 1977, Environmental choice, human behavior, and residential satisfaction (Oxford University Press: New York)

Murdie R A, Borgegård L-E, 1998, "Immigration, Spatial Segregation and Housing Segmentation of Immigrants in Metropolitan Stockholm, 1960-95" Urban Studies 35 1869-1888

Permentier M, van Ham M, Bolt G, 2009, "Neighbourhood reputation and the intention to leave the neighbourhood" Environment and Planning A 41 21622180

Quillian L, Bruch E, 2010, Race and Class in Neighborhood Mobility: A Conditional Logit Model of Neighbourhood Migration Paper presented at the meeting of the Population Association of America, Dallas, Texas, April 2010

Schelling T C, 1969, "Models of segregation" The American Economic Review 59 488-93

Schelling T C, 1971, "Dynamic models of segregation" Journal of mathematical Sociology 1 143-186

Small, M L, Feldman, J, 2011, "Ethnographic Evidence, Heterogeneity, and Neighbourhood Effects after Moving To Opportunity" in Neighbourhood Effects Research: New Perspectives Eds M van Ham, D Manley, N Bailey, L Simpson, D Maclennan (Dordrecht: Springer)

South S J, Crowder K D, 1997, "Escaping Distressed Neighbourhoods: Individual, Community and Metropolitan Influences" American Journal of Sociology 102 1040-4084

South S J, Crowder K D, 1998, "Leaving the 'Hood': Residential Mobility between Black, White and Integrated Neighbourhoods" American Sociological Review 63 17-26

Turner M A, Ross S L, Galster G C, Yinger J, 2002, Discrimination in Metropolitan Housing Markets: National Results from Phase I HDS 2000 (The Urban Institute: Washington D.C)

van Ham M, Clark W A V, 2009, "Neighbourhood mobility in context: household moves and changing neighbourhoods in the Netherlands" Environment and Planning A 41 1442-1459

van Ham M, Feijten P, 2008, "Who wants to leave the neighbourhood? The effect of being different from the neighbourhood population on wishes to move" Environment and Planning A 40 1151-1170

van Ham M, Manley D, 2009, "Social Housing Allocation, Choice and Neighbourhood Ethnic Mix in England" Journal of Housing and the Built Environment 24 407-422 
van Ham M, Manley D, 2010, "The effect of neighbourhood housing tenure mix on labour market outcomes: a longitudinal investigation of neighbourhood effects" Journal of Economic Geography 10 257-282 
Table 1. Descriptive statistics of neighbourhoods in 2001 (excludes neighbourhoods with under 50 inhabitants).

\begin{tabular}{|lcccc|}
\hline & Mean & Std Dev. & Minimum & Maximum \\
\cline { 2 - 5 } Number of Inhabitants & 1103 & 817.9 & 68 & 3251 \\
\% Foreign Born & 13.5 & 9.4 & 2.8 & 51.0 \\
\% With Children under 18 & 44.3 & 18.1 & 8.1 & 86.1 \\
\% Students & 14.2 & 10.0 & 4.9 & 64.3 \\
\% With Low Education (compulsory school) & 12.3 & 5.3 & 1.1 & 26.4 \\
\% Non-employed (age 20-64) & 19.5 & 9.2 & 4.1 & 47.6 \\
\% Receiving Social Benefits & 2.9 & 3.9 & 0.0 & 23.1 \\
\% Public Renters & 9.2 & 19.3 & 0.0 & 95.8 \\
Median Annual Disposable Income (100000 SEK ${ }^{\mathrm{a}}$ ) & 2.7 & 1.0 & 0.8 & 4.8 \\
\hline $\mathrm{N}$ & 122 \\
\hline a10 SEK is about $€ 1$ & \multicolumn{5}{l}{} \\
\hline
\end{tabular}

Source: Author's calculations using data from GeoSweden.

Table 2. Descriptives of moving households between 1997 and 2006, in comparison to all households in the city in 2001 (percentages except income).

\begin{tabular}{|c|c|c|}
\hline \multirow[b]{2}{*}{ Ethnicity } & \multirow[t]{2}{*}{$\begin{array}{c}\text { Moving households } \\
\text { 1997-2006 } \\
\end{array}$} & \multirow[t]{2}{*}{ All households $2001^{3}$} \\
\hline & & \\
\hline All Swedish born & 79.4 & 81.6 \\
\hline All Foreign born & 17.2 & 15.2 \\
\hline Mixed ethnicity & 3.4 & 3.2 \\
\hline \multicolumn{3}{|l|}{ Family Composition } \\
\hline Couple & 6.5 & 11.8 \\
\hline Couple with children & 12.4 & 16.3 \\
\hline Single Parent & 6.4 & 7.6 \\
\hline Single & 74.7 & 64.4 \\
\hline Student in household & 30.8 & 19 \\
\hline \multicolumn{3}{|l|}{ Education } \\
\hline Compulsory School & 9.2 & 9.4 \\
\hline High School & 35.1 & 43.5 \\
\hline University & 55.7 & 35.7 \\
\hline \multicolumn{3}{|l|}{ Employment } \\
\hline All Employed & 59.3 & 54.6 \\
\hline All Non-Employed & 30.8 & 21.4 \\
\hline Mixed Employment status & 3.9 & 4.6 \\
\hline Age $65+$ & 6.0 & 19 \\
\hline Mean Disposable Income (100 000 SEK) & 2.02 & 2.09 \\
\hline Social Allowances Recipient & 8.2 & 4.7 \\
\hline \multicolumn{3}{|l|}{ Tenure } \\
\hline Home Ownership & 25.9 & 17.2 \\
\hline Cooperative Ownership & 33.6 & 39.4 \\
\hline Private Rental & 24.7 & 19.6 \\
\hline Public Rental & 15.8 & 10 \\
\hline $\mathbf{N}$ & 130,231 & 79,143 \\
\hline
\end{tabular}

Source: Author's calculations using data from GeoSweden.

\footnotetext{
${ }^{3}$ Due to missing data, data distributions do not always sum up to $100 \%$.
} 
Table 3. Descriptive statistics of neighbourhoods in quintiles according to turnover rates (percentages except age and income).

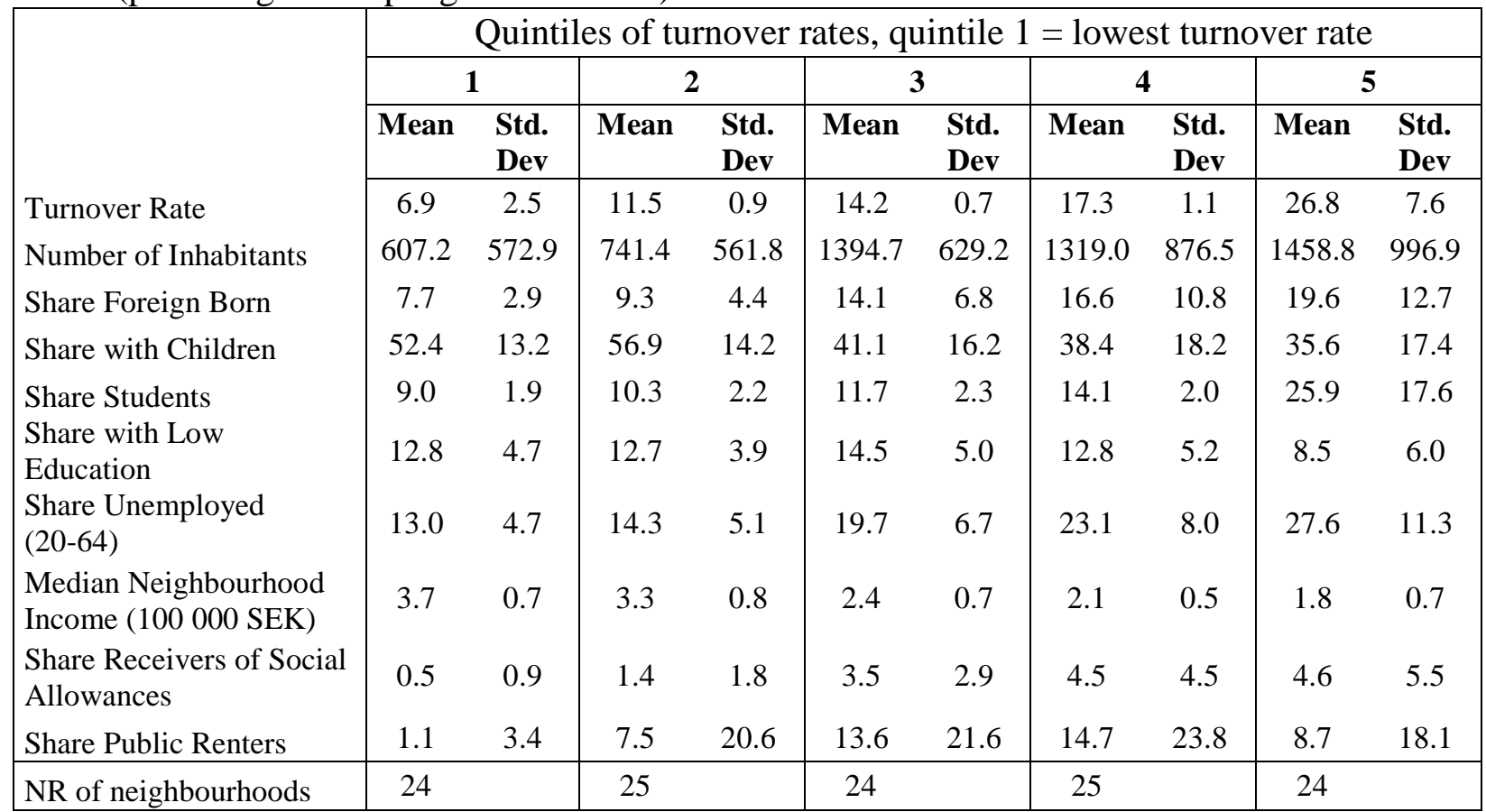

Source: Author's calculations using data from GeoSweden. 
Figure 1. Maps showing Uppsala neighbourhoods according to (a) turnover rate, (b) median income and(c) share of foreign born.
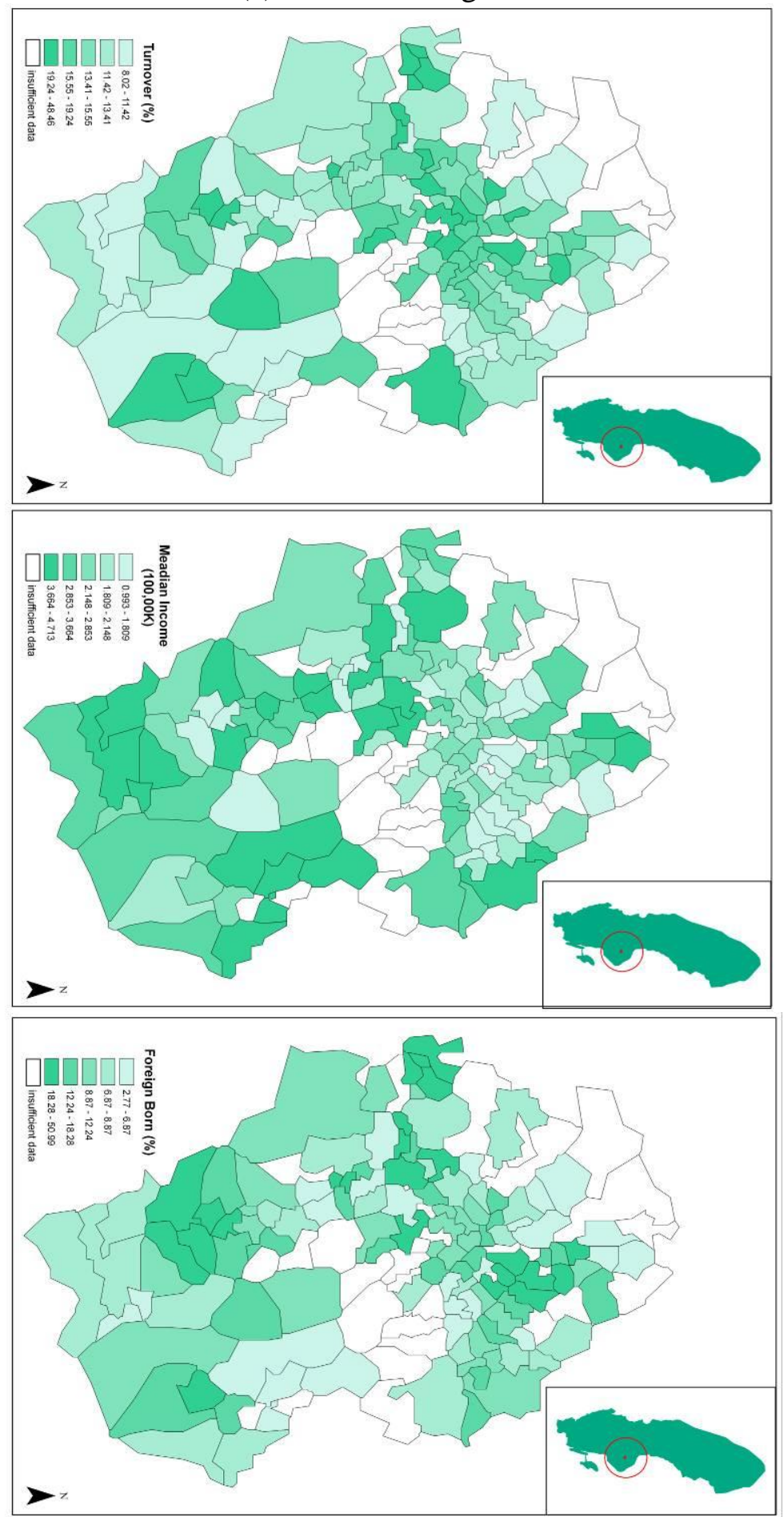

Source: Author's calculations using data from GeoSweden. 
Table 4. Conditional Logit Model of neighbourhood choice (with random choice set of 10 neighbourhoods).

\begin{tabular}{|c|c|c|c|c|c|c|}
\hline & \multicolumn{3}{|c|}{ Model 1} & \multicolumn{3}{|c|}{ Model 2} \\
\hline & \multicolumn{2}{|c|}{ Std. } & Sign. & Coefficient & $\begin{array}{c}\text { Std. } \\
\text { Error }\end{array}$ & Sign. \\
\hline \multicolumn{7}{|l|}{$\begin{array}{l}\text { Median Neigbourhood Income (100 } 000 \text { SEK) } \\
\text { (MI) }\end{array}$} \\
\hline MI x Income in 1st Quintile (lowest) & -1.3168 & 0.0075 & $* * *$ & -1.0398 & 0.0110 & $* * *$ \\
\hline MI x Income in 2nd Quintile & -0.9085 & 0.0077 & $* * *$ & -0.9580 & 0.0109 & $* * *$ \\
\hline MI x Income in 3rd Quintile & -0.6300 & 0.0086 & $* * *$ & -0.7724 & 0.0114 & $* * *$ \\
\hline MI x Income in 4th Quintile & -0.3143 & 0.0096 & $* * *$ & -0.5541 & 0.0124 & $* * *$ \\
\hline MI x Income in 5th Quintile & -0.0194 & 0.0105 & & -0.3047 & 0.0131 & $* * *$ \\
\hline \multicolumn{7}{|l|}{ Share Foreign born $(\mathrm{FB})$} \\
\hline FB x Swedish born & & & & -0.0082 & 0.0007 & $* * *$ \\
\hline FB $x$ Foreign born & & & & 0.0328 & 0.0008 & $* * *$ \\
\hline FB x Mixed Ethnicity Household & & & & 0.0069 & 0.0018 & $* * *$ \\
\hline \multicolumn{7}{|l|}{ Share with Children $(\mathrm{Ch})$} \\
\hline Ch x Couple & & & & 0.0008 & 0.0007 & \\
\hline Ch x Couple with Children & & & & 0.0217 & 0.0006 & $* * *$ \\
\hline Ch x Single Parent & & & & -0.0001 & 0.0005 & \\
\hline Ch $x$ Single & & & & -0.0112 & 0.0004 & $* * *$ \\
\hline \multicolumn{7}{|l|}{ Share Students (St) } \\
\hline St $\mathrm{x}$ Student in Household & & & & 0.0335 & 0.0004 & $* * *$ \\
\hline St $x$ No Student in Household & & & & -0.0199 & 0.0005 & $* * *$ \\
\hline \multicolumn{7}{|l|}{ Share with Low Education (LE) } \\
\hline LE x No High School Degree & & & & 0.0871 & 0.0025 & $* * *$ \\
\hline LE x High School Degree & & & & 0.0066 & 0.0009 & $* * *$ \\
\hline LE x University Education & & & & -0.0495 & 0.0013 & $* * *$ \\
\hline \multicolumn{7}{|l|}{ Share Non-Employed (20-64) (NE) } \\
\hline NE x All Employed & & & & -0.0363 & 0.0007 & $* * *$ \\
\hline NE x All Non-employed (20-64) & & & & -0.0247 & 0.0007 & $* * *$ \\
\hline NE x Mixed Employment status (20-64) & & & & -0.0272 & 0.0015 & $* * *$ \\
\hline NE x Retired (age 65 or older) & & & & -0.0402 & 0.0014 & $* * *$ \\
\hline \multicolumn{7}{|l|}{ Share Social Allowance Recipients (SA) } \\
\hline SA x Household receive Social Allowances & & & & 0.1175 & 0.0019 & $* * *$ \\
\hline SA x Household do not receive Social Allowance & & & & 0.0624 & 0.0013 & $* * *$ \\
\hline \multicolumn{7}{|l|}{ Share Public Renters (PuR) } \\
\hline PuR x Home Owner & & & & -0.0064 & 0.0004 & $* * *$ \\
\hline PuR x Owner of Cooperative Flat & & & & -0.0052 & 0.0003 & $* * *$ \\
\hline PuR x Private Renter & & & & -0.0042 & 0.0004 & $* * *$ \\
\hline PuR x Public Renter & & & & 0.0095 & 0.0004 & $* * *$ \\
\hline Observations & 1302310 & & & 1302310 & & \\
\hline Log Likelihood & -263067.47 & & & -245947.17 & & \\
\hline Pseudo-R ${ }^{2}$ & 0.1263 & & & 0.1831 & & \\
\hline
\end{tabular}

Source: Author's calculations using data from GeoSweden. 
Appendix A: Conditional Logit Model of neighbourhood choice (with all neighbourhoods in choice set) with a $25 \%$ sample of moves.

\begin{tabular}{|c|c|c|c|c|c|c|}
\hline & \multicolumn{3}{|c|}{ Model 1} & \multicolumn{3}{|c|}{ Model 2} \\
\hline & Coefficient & $\begin{array}{c}\text { Std. } \\
\text { Error }\end{array}$ & Sign. & Coefficient & $\begin{array}{c}\text { Std. } \\
\text { Error }\end{array}$ & Sign. \\
\hline \multicolumn{7}{|l|}{$\begin{array}{l}\text { Median Neigbourhood Income (100 } 000 \text { SEK) } \\
\text { (MI) }\end{array}$} \\
\hline MI x Income in 1st Quintile (lowest) & -1.489 & 0.015 & $* * *$ & -0.945 & 0.021 & $* * *$ \\
\hline MI x Income in 2nd Quintile & -0.968 & 0.015 & $* * *$ & -0.831 & 0.021 & $* * *$ \\
\hline MI x Income in 3rd Quintile & -0.686 & 0.017 & $* * *$ & -0.681 & 0.022 & $* * *$ \\
\hline MI x Income in 4th Quintile & -0.355 & 0.019 & $* * *$ & -0.467 & 0.024 & $* * *$ \\
\hline MI x Income in 5th Quintile & -0.089 & 0.021 & $* * *$ & -0.271 & 0.026 & $* * *$ \\
\hline \multicolumn{7}{|l|}{ Share Foreign born (FB) } \\
\hline FB x Swedish born & & & & 0.002 & 0.001 & \\
\hline FB x Foreign born & & & & 0.043 & 0.002 & $* * *$ \\
\hline FB x Mixed Ethnicity Household & & & & 0.019 & 0.003 & $* * *$ \\
\hline \multicolumn{7}{|l|}{ Share with Children $(\mathrm{Ch})$} \\
\hline Ch x Couple & & & & -0.005 & 0.001 & $* * *$ \\
\hline Ch x Couple with Children & & & & 0.015 & 0.001 & $* * *$ \\
\hline Ch $x$ Single Parent & & & & -0.009 & 0.001 & $* * *$ \\
\hline Ch x Single & & & & -0.019 & 0.001 & $* * *$ \\
\hline \multicolumn{7}{|l|}{ Share Students $(\mathrm{St})$} \\
\hline St $x$ Student in Household & & & & 0.014 & 0.001 & $* * *$ \\
\hline St x No Student in Household & & & & -0.028 & 0.001 & $* * *$ \\
\hline \multicolumn{7}{|l|}{ Share with Low Education (LE) } \\
\hline LE x No High School Degree & & & & 0.060 & 0.003 & $* * *$ \\
\hline LE x High School Degree & & & & 0.013 & 0.002 & $* * *$ \\
\hline LE x University Education & & & & -0.063 & 0.002 & $* * *$ \\
\hline \multicolumn{7}{|l|}{ Share Non-Employed (20-64) (NE) } \\
\hline NE x All Employed & & & & -0.012 & 0.002 & $* * *$ \\
\hline NE x All Non-employed (20-64) & & & & 0.007 & 0.001 & $* * *$ \\
\hline $\begin{array}{l}\text { NE x Mixed Employment status (20- } \\
64)\end{array}$ & & & & -0.001 & 0.003 & \\
\hline NE $x$ Retired (age 65 or older) & & & & -0.017 & 0.003 & $* * *$ \\
\hline \multicolumn{7}{|l|}{ Share Social Allowance Recipients (SA) } \\
\hline SA x Household receive Social Allowa & aces & & & 0.072 & 0.003 & $* * *$ \\
\hline SA x Household do not receive Social & Allowances & & & 0.022 & 0.003 & $* * *$ \\
\hline \multicolumn{7}{|c|}{ Share Public Renters (PuR) } \\
\hline PuR x Home Owner & & & & -0.006 & 0.001 & $* * *$ \\
\hline PuR x Owner of Cooperative Flat & & & & -0.005 & 0.001 & $* * *$ \\
\hline PuR x Private Renter & & & & -0.003 & 0.001 & $* * *$ \\
\hline PuR x Public Renter & & & & 0.009 & 0.001 & $* * *$ \\
\hline Observations & 3917298 & & & 3917298 & & \\
\hline Log Likelihood & -142656.63 & & & -137079.33 & & \\
\hline Pseudo-R ${ }^{2}$ & 0.0773 & & & 0.1133 & & \\
\hline
\end{tabular}

Source: Author's calculations using data from GeoSweden. 